\title{
REVIEW
}

\section{Lingual Nerve Entrapment in Muscular and Osseous Structures}

\section{Maria Piagkou*, Theano Demesticha, Giannoulis Piagkos, Androutsos Georgios, Skandalakis Panagiotis}

Department of Anatomy, School of Medicine, Faculty of Health Sciences, University of Athens, Athens, Greece

\begin{abstract}
Running through the infratemporal fossa is the lingual nerve (i.e. the third branch of the posterior trunk of the mandibular nerve). Due to its location, there are various anatomic structures that might entrap and potentially compress the lingual nerve. These anatomical sites of entrapment are: (a) the partially or completely ossified pterygospinous or pterygoalar ligaments; (b) the large lamina of the lateral plate of the pterygoid process; and (c) the medial fibers of the anterior region of the lateral pterygoid muscle. Due to the connection between these nerve and anatomic structures, a contraction of the lateral pterygoid muscle, for example, might cause a compression of the lingual nerve.
\end{abstract}

Any variations in the course of the lingual nerve can be of clinical significance to surgeons and neurologists because of the significant complications that might occur. To name a few of such complications, lingual nerve entrapment can lead to: (a) numbness, hypoesthesia or even anesthesia of the tongue's mucous glands; (b) anesthesia and loss of taste in the anterior two-thirds of the tongue; (c) anesthesia of the lingual gums; and (d) pain related to speech articulation disorder. Dentists should, therefore, be alert to possible signs of neurovascular compression in regions where the lingual nerve is distributed.

Keywords lingual nerve, compression, pterygospinous ligament, lateral pterygoid muscle

Received Jun. 29, 2010; Revision accepted Aug. 23, 2010

\section{Introduction}

Entrapment of the lingual nerve (LN) takes place when different anatomical structures compress the $\mathrm{LN}$ at various points along its course. A typical site of LN compression is the infratemporal fossa (ITF) (Nayak et al., 2008); situated below the middle cranial fossa of the skull, between the pharynx and the ramus of the mandible. This retromaxillary area contains the muscles for mastication, the pterygoid venous plexus, the maxillary artery (MA), and the ramification of the mandibular nerve $(\mathrm{MN})$ (Figure 1) (Prades et al., 2003).

The MN descends through the foramen ovale (FO) into the ITF and, in close relation to the lateral pterygoid muscle (LPt), then which divides into a smaller anterior trunk containing the anterior deep temporal nerve (ADTN), the posterior deep

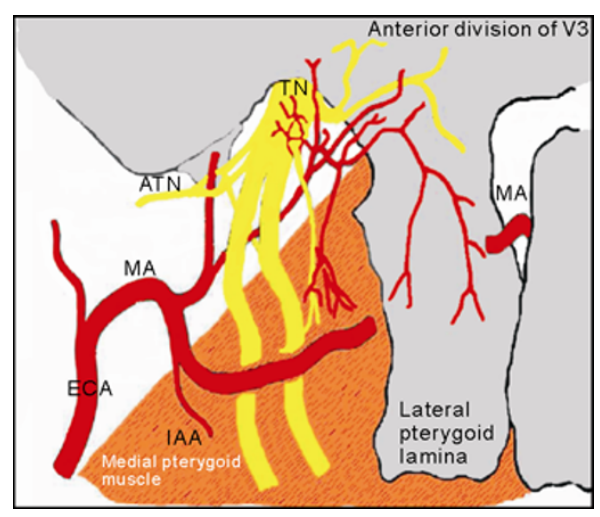

Figure 1 Relationship and terminal distribution of the maxillary artery (MA) and accessory meningeal artery in the infratemporal fossa

TN: trigeminal nerve; ECA: external carotid artery; IAA: inferior alveolar artery; ATN: auriculotemporal nerve; MA: maxillary artery.

Int J Oral Sci, 2(4): 181-189, 2010 - 181 - 
temporal nerve (PDTN), and the masseteric nerves that pass between the roof of the ITF and the LPt. The posterior trunk, which contains the LN, the inferior alveolar nerve (IAN), and the auriculotemporal nerve (ATN), descends medially to the LPt, a site of potential LN entrapment (Isberg et al., 1987; Loughner et al., 1990).

Occasionally, the FO can be covered by a bony lamina or bridge, which results from ossification of the ligament between the lateral pterygoid process and the sphenoid spine (Kapur et al., 2000). The formation of these osseous structures are, therefore, the outcome of secondary ossification in surrounding ligaments (Peuker et al., 2001).

Lang and Hetterich (1983) asserted that the pterygospinous bar was present in human skulls as young as 5 years of age, in which adjacent sutures were still evident. From a clinical standpoint, ossified ligaments have become very important when considering different methods of block anesthesia for the MN (Lepp and Sandner, 1968). Additionally, these osseous structures may be implicated in the production of various neurological disturbances (Shaw, 1993). For example, Krmpotic-Nemanic et al. (2001) noted that a pterygospinous foramen replacing the FO could provoke trigeminal neuralgia (TGN) (Figure 2).

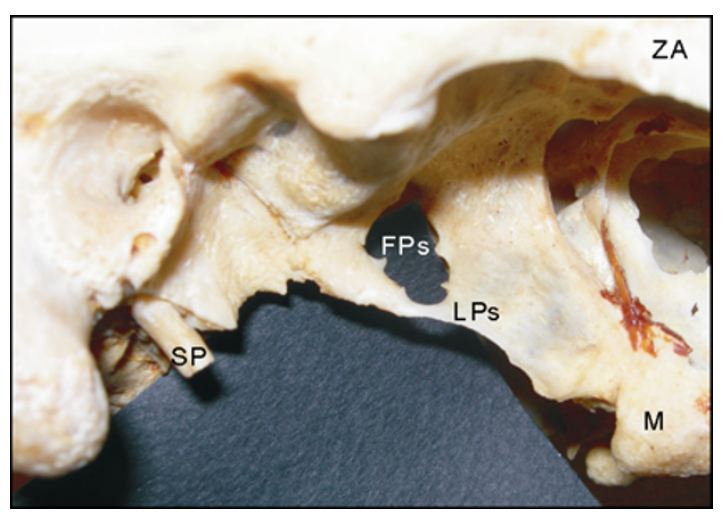

Figure 2 Complete pterygospinous osseous bar and the enlarged pterygospinous foramen on the left side of a male skull

M: mandible; LPP: lateral pterygoid plate; FPs: pterygospinous foramen; OC: occipital condyle; ZA: zygomatic arch; SP: styloid process.

Variations in the course of LN are important considerations for effective administration of local anaesthesia, as well as for successful outcomes in numerous dental, oncological and reconstructive procedures (Akita et al., 2001). These variations can cause serious implications to any surgical intervention in the region and may lead to a false differential diagnosis for a neurological condition. If abnormal branches of the $\mathrm{MN}$ were to occur in combination with ossified ligaments, then cutaneous sensory fibers might pass through one of the foramina formed by the ossified bars (Shaw, 1993). Entrapment of the LN can cause numbness in all regions innervated by it, which could result in loss of taste to various extents, and could also generate pain during speech or other articulatory processes (Peuker et al., 2001).

\section{The typical course of the lingual nerve}

The LN is a major branch of the posterior trunk of the $\mathrm{MN}$ at the FO. It begins its course from the ITF running laterally to the MPt, then to the medial and ventral regions of the IAN (Kim et al., 2004; Trost et al., 2009). The LN runs between the tensor veli palatini and LPt muscles, where it is then joined by the chorda tympani (CT) branch of the facial nerve. The CT innervates taste fibers for the anterior two-thirds of the tongue, as well as parasympathetic fibers for the submandibular and sublingual salivary glands (Zur et al., 2004). The LN proceeds downwards and then forwards along the surface of the MPt, and progresses towards the medial surface of the mandibular ramus until it reaches the bone located a few millimeters below and behind the junction of the vertical and horizontal rami of the mandible; thereby lying anteriorly to, and slightly deeper than, the IAN. The LN then passes below the mandibular attachment of the superior pharyngeal constrictor and pterygomandibular raphe (closely applied to the periosteum of the medial surface of the mandible), until it lies opposite to the posterior root of the third molar; the site whereby it is covered only by the gingival mucoperiosteum. On the upper end level of the mylohyoid line, the LN continues horizontally along the superior surface of the mylohyoid muscle, courses in close relation to the upper pole of the submandibular gland, and then releases its fibers to the submandibular ganglion.

The LN is closely situated to the posterior part 
of the sublingual gland and divides into numerous branches entering the tongue's tissue. The LN first courses along the surface of the styloglossus, then along the lateral surface of the hyoglossus and genioglossus, before dividing into terminal branches which supply the overlying lingual mucosa (Peuker et al., 2001). In addition to receiving the $\mathrm{CT}$ and a branch from the IAN, the $\mathrm{LN}$ is connected to the submandibular ganglion by two to three branches and, at the anterior margin of the hyoglossus, it forms connecting loops with fibers of the hypoglossal nerve. The LN supplies general sensation to the mucosa, the floor of the mouth, the lingual gingival, and the mucosa of the anterior two-thirds of the tongue (an area posteriorly overlapped by lingual fibers of the glossopharyngeal nerve (Rusu et al., 2008). The nerve transfers neural sensory fibers for general sensitivity (pressure, temperature, pain, touch) and for taste sensation to the anterior part of the tongue via the $\mathrm{CT}$. The medial and lateral branches of the $\mathrm{LN}$ have anatomical connections with the hypoglossal nerve in the tongue body. In view of this connection, precise knowledge of the anatomical distribution of the LN may, therefore, assist oral surgeons in executing safe and effective procedures (Zur et al., 2004).

The LN can sometimes be entrapped, either through: (a) an ossified pterygospinous or pterygoalar ligament (located on the outer part of the cranial base); (b) an extremely wide lateral lamina on the pterygoid process of the sphenoid bone; or (c) the medial fibers of the anterior region of the lateral pterygoid muscle (von Ludinghausen et al., 2006). Recently, it was proposed that some cases of temporomandibular joint syndrome or myofascial pain syndrome could be a result of nerve entrapment in the ITF (Koppel and Thompson, 1976).

\section{Muscular and osseous structures of lingual nerve entrapment}

\section{Ossified ligaments}

The osseous bridges that are occasionally observed in the exocranial region of the FO are the outcome of secondary ossification of the fibrous structures. A ligament's ossification may compress the neighbouring structures and provoke complications in regional surgery (Ozdogmus et al., 2003).

In 1835, Filippo Civinini observed that in some cases the lateral pterygoid plate extends posteriorly to contact the base of the spinal process of the sphenoid bone. In 1837, Civinini described the ossification of the pterygospinous ligament in varying degrees, as well as the formation of the "Civinini bar" located medial to the FO. The result was the formation of the pterygospinous foramen, through which passed the medial pterygoid vessels and nerves, as well as branches of the MN which innervate the muscles for mastication (Tebo, 1968; Peker et al., 2002). The pterygospinous ligament is occasionally replaced by muscular formations, such as the pterygospinous muscle when inserted into the TMJ capsule and extended to the articular disc (von Ludinghausen et al., 2006).

Civinini found complete ossification of the pterygospinous ligament in $2 \%-3 \%$ of the dry skulls examined (Figure 3).

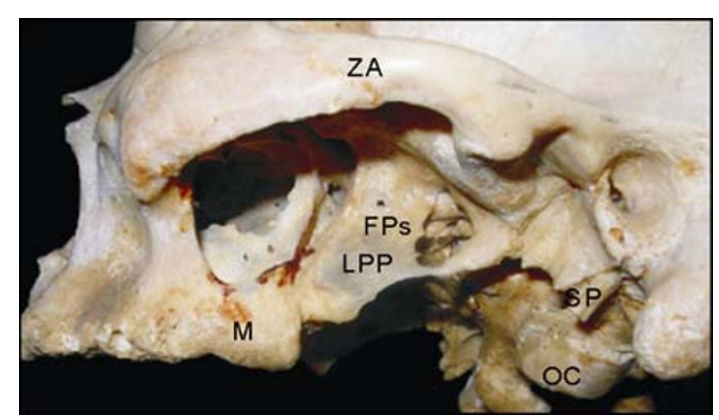

Figure 3 Complete pterygospinous osseous bar on the right side of a skull

M: mandible; FPs: pterygospinous foramen; OC: occipital condyle;

ZA: zygomatic arch; SP: styloid process.

Other authors reported a prevalence of $3 \%-$ $4.3 \%$ of pterygospinous bars completely ossified in the skulls of sociopaths and criminals (Lepp and Sandner, 1968). In 1862, Hyrtl described a canal on the lower base surface of the sphenoid's great wing, into which the ramus crotaphitico-buccinatorius of the $\mathrm{MN}$ entered immediately after its separation from the MN division (Hyrtl, 1862; Chouke, 1946). This canal, labelled as porus crotaphitico-buccinatorius, can be confused with those foramina occasionally formed by the union of the long and wide protrusions of the posterior 
margin of the external pterygoid lamina with the spina angularis of the sphenoid. Through the pterygoalar foramen pass some of the motor fibers of the TN (the nerve which extends to the buccinator muscle, the lateral pterygoid muscle, and the temporalis muscle). In some cases, the nerve to the masseter muscle, some veins of the pterygoid venous plexus and a few small arteries may also pass through the TN (Skrzat et al., 2005). (Figure 4).

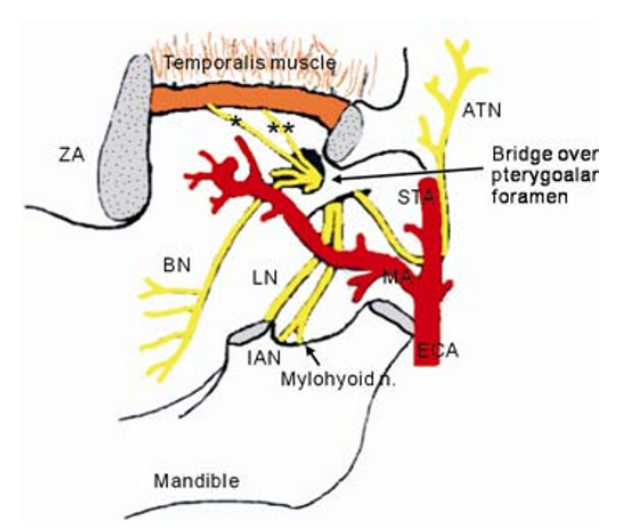

Figure 4 The existence of the pterygoalar foramen and the neigh-bouring anatomical structures (distribution of the branches of the mandibular nerve and the maxillary artery). This foramen is a site of lingual nerve entrapment (Chouke 1946-modified)

*: anterior deep temporal nerve; **: posterior deep temporal nerve; BN: buccal nerve; LN: lingual nerve; IAN: inferior alveolar nerve; ATN: auriculotemporal nerve; ECA: external carotid artery; MA: maxillary artery; STA: superficial temporal artery; ZA: zygomatic arch.

De Froe and Wagenaar (1935) were the first to recognize radiographically the pterygoalar bar. Based on X-rays of the FO, they highlighted that the presence of the ossified pterygoalar ligament can interfere with, and even stop, the neural projection of the semilunar ganglion. In an anatomical study of European skulls, they observed the presence of the pterygospinous foramen in $5 \%$ of the cases studied. A corresponding study of over 6000 sample skulls confirmed their results (Chouke, 1949). In 1951, Chouke and Hodes found the pterygoalar bar in $7.05 \%$ of their 1234-patient sample (in $0.89 \%$ bilaterally). In several cases, this osseous bar is so hard and rough that the FO is difficult to distinguish. By contrast, in skulls where the bar is thin, the FO is easy to decipher, yet anesthetization of the $\mathrm{MN}$ remains impossible (Figure 5).

The pterygoalar ligament may lie along the lateral or medial margin of the FO, or across its lumen (James et al., 1980). Lepp and Sandner (1968) reported that these osseous bridges were present in about $8 \%-10 \%$ of the population and that the pterygoalar ligament was ossified more often than the pterygospinous ligament. Lang (1995) found the pterygospinous ligament ossified in $2 \%-7 \%$ of Caucasians and in $12 \%-13 \%$ of African skulls.

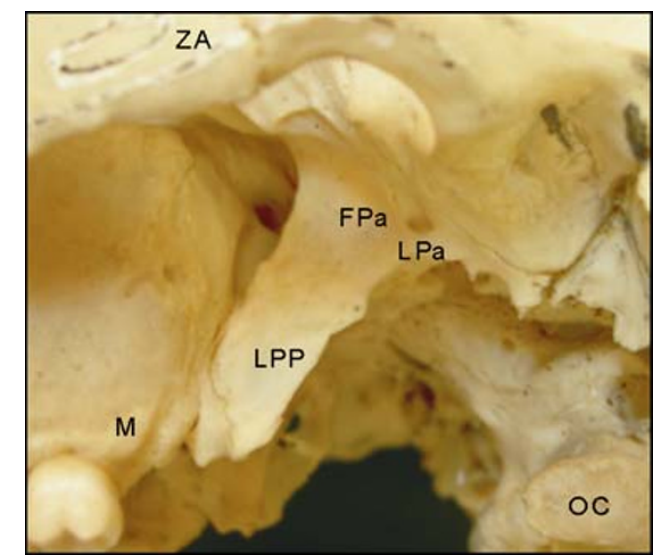

Figure 5 Complete pterygoalar brigde and the pterygoalar foramen on the left side of a skull

M: mandible; LPP: lateral pterygoid plate; FPa: pterygoalar foramen; OC: occipital condyle.

The pterygospinous and pterygoalar osseous bridges, and related foramina, generate considerable interest within morphological, anthropological and, especially, clinical circles. In the typical pithecoid, the pterygospinous bar is complete and passes lateral to the FO; in lemurs, it passes medially to the FO; and in humans and anthropoids, it is usually incomplete (Jones, 1931). A wide pterygospinous bar exists in all skulls of herbivores, rodentia, carnivores and mature monkeys (von Ludinghausen et al., 2006). The pterygoalar bar and related foramen are normally present in lower animals and persist in $8 \%$ of Hawaiian human skulls (Patnaik et al., 2001). Together, these findings constitute criteria for race differentiation (Jones, 1931).

The pterygospinous bars are more frequent in males than in females (Chouke, 1947) and also show crosscultural variations (Peker et al., 2002). For example, Anatolian males demonstrate some 
similarity to male Italians, American Caucasians, African-Americans and Native Americans; but no similarity to Dutch and South African males. Moreover, the dissimilarities are greater amongst females of various ethnic populations (Peker et al., 2002). Chouke $(1946,1947)$ reported a tendency for asymmetry in both genders, with preference for a unilateral occurrence on the left side. By constrast, De Villiers (1968) found the pterygoalar bar more commonly located on the right side.

In terms of the pterygospinous foramen, it has been found to be present four times as often in the skulls of Caucasian males than of African males ( $8.38 \%$ and $1.95 \%$ respectively). In females, this ratio was much less pronounced at approximately 2 to $1(3.01 \%$ and $1.59 \%$ respectively). The pterygospinous foramen was observed in most Caucasian females $(40 \%)$ in the second decade; the lowest incidence being in the sixth decade $(6.90 \%)$. Interestingly, no pterygospinous foramina were observed at all in the 1930s and 1940s (Chouke, 1946). Zakrzewska (1990) reported that the pterygospinous foramen predominantly occurred either bilaterally or on the left side exclusively. Shaw (1993) found complete (or partially complete) pterygospinous foramen on the right side in $22 \%$ of the skulls, on the left side in $35.6 \%$, and bilaterally in $42.5 \%$ (Figure 6). The pterygoalar foramen was found four times as often in the skulls of Africans than in those of Caucasians; the ratio for males and females being the same at $4: 1$ (Chouke, 1946).

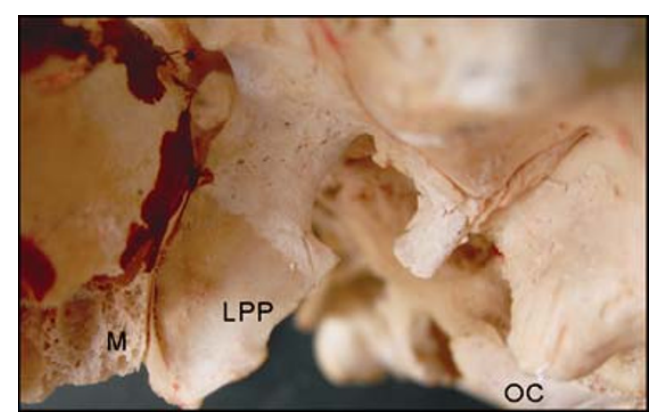

Figure 6 Incomplete pterygoalar bar on the left side of a skull

M: mandible; LPP: lateral pterygoid plate; OC: occipital condyle;

*: pterygospinous bar (tips of ossification).

The pterygospinous and pterygoalar foramina being completely formed in the skulls of some children suggest the possibility that genetic factors may be involved. Similarly, the TGN has been reported to occur in more than one member of a given nuclear family, as well as within different generations of that family's extended relatives (Yoshimasu et al., 1972).

Despite their rarity as cranial features, the presence of these ossified ligaments has significant clinical implications. For example, during efforts to relieve the TGN, ossified ligaments can obstruct the passage of the needle into the FO, thereby disabling the anesthetization of the trigeminal ganglion or the MN (Skrzat et al., 2005). The presence of the ossified pterygospinous ligament may compress on surrounding neurovascular structures, causing lingual numbness and pain associated with speech impairment (Peuker et al., 2001). Considering the close relationship of the $\mathrm{CT}$, it may also be compressed by the anomalous bar of bone. Involvement of the CT would result in abnormal taste sensation in the anterior two-thirds of the tongue (Das and Paul, 2007). Such compression may also produce a partial lesion of the nerve, which can lead to a distortion of signalling patterns or ectopic impulses within the damaged nerve fibers.

The presence of an ossified pterygospinous ligament, or an atypical position of the FO and neighbouring osseous structures, may affect the distribution pattern of the $\mathrm{MN}$ as it passes through the FO. In such cases, the main trunk of the $\mathrm{MN}$ is redirected laterally and its dividing neural routes (the LN and IAN) have to cross the extended lateral pterygoid plate. Because of this abnormal course, there is greater risk for neuralgia occurring due to the nerves becoming entrapped or compressed between the osseous structures and muscles (von Ludinghausen et al., 2006). Intermittent compression of the nerves by adjacent blood vessels may also have a role in the etiology of the TGN (Shaw, 1993). During procedures to successfully treat the TGN, the ossification of the pterygospinous ligament may not only interrupt the anesthesia of the trigeminal ganglion but also obstruct the anesthesia of the TN. Radiographically, the calcification and/or ossification of the pterygospinous ligament can present a picture of a divided FO on the axial projection of the skull (Newton and Potts, 1971). The authors must, 
therefore, emphasize the importance of ensuring radiographic control of the skull base extracranially while anesthetizing the trigeminal ganglion via the lateral subzygomatic route (Kapur et al., 2000). The anesthesia may fail when the needle reaches a depth of $35 \mathrm{~mm}$ and crosses the partially or completely ossified pterygospinous and pterygoalar ligaments (Kapur et al., 2000). It has also been reported that thermo-coagulation of the trigeminal ganglion may be difficult in the presence of these ossified ligaments (Lang, 1995).

Kapur et al. (2000) found incomplete ossified pterygospinous ligaments bilaterally in $3.93 \%$ of the skulls of adults over 50 years old (Figure 6). A pterygoalar foramen was found bilaterally in only 2 skulls $(0.97 \%)$. A complete unilateral pterygoalar bar has been found in about $5 \%$ of the Anatolian skulls, with greater frequency in the African population, while the incidence of the bilateral pterygoalar bar is very low (1\%). The occurrence of the pterygoalar bar and foramen may, therefore, vary from $1 \%$ to $10 \%$. Antonopoulou et al. (2008), in their anatomical study of 50 adult dry skulls (male and female), found incomplete pterygospinous bars in 7 skulls bilaterally and one incomplete pterygoalar bar in a single skull bilaterally. A complete pterygospinous bar occurred in only one skull bilaterally. While applying conductive anaesthesia on the MN via the lateral subzygomatic route, the presence of ossified structures within the lateral plate's posterior border of pterygoid process should be considered and verified.

Peuker et al. (2001) observed an unusual course of the LN in an 82-year-old male cadaver, whereby entrapment of the nerve occurred between a widely ossified pterygospinous ligament and the MPt. Peker et al. (2002) observed entrapment of the MN during its course through the pterygoalar ligament on the left side of the cadaver of a 70 year-old man. Compression of sensory branches of the MN by the masticatory muscles is a possible cause of neuropathology (neuralgia or paresthesia). Shaw (1993) suggested that traction or compression of cutaneous fibers of the $\mathrm{MN}$, due to bone overgrowth around the margins of the pterygospinous or pterygoalar foramen, could be responsible for a small proportion of cases of TGN. Chronic, progressive compression of the $\mathrm{LN}$, due to slow bone deposition, may cause physical damage to the axons at the entrapment site, as well as to neighbouring segments of the nerve.

\section{The extremely large pterygoid plate}

The lateral lamina of the pterygoid process together with the MPt has been seen to form the medial wall of the ITF. Elongation of the lateral lamina of the pterygoid process could result in weakening of the MPt and paresthesia of the inner aspect of the cheek. LN compression could lead to a weakening of taste transmission from the taste buds located on the anterior two thirds of the tongue unilaterally (Krmpotic-Nemanic et al., 1999). In cases of extremely large lateral lamina, the LN and the IAN in the region of the ITF are forced to take a long curved course, following the shape of the enlarged lamina. During contraction of the pterygoid muscles, both nerves can be compressed. Krmpotic-Nemanic et al. (1999) observed that the appearance of the large lateral lamina was in general unilateral. In a single case a large lateral lamina was found bilaterally. In five out of 100 examined dry adult skulls, the existence of a degenerated and wide lateral plate of the pterygoid process measuring laterally $24 \mathrm{~mm}$ to $32 \mathrm{~mm}$ was established (Krmpotic-Nemanic et al, 1999). In the anatomical study of Skrzat et al, (2005) elongation of the lateral pterygoid plate could result in weakening of the MPt and paresthesia of the buccal region. Lateral pterygoid plate forms an important landmark for mandibular anesthesia and any anomaly in the lateral pterygoid plate is bound to confuse anesthetists. A wider lateral pterygoid plate may pose difficulty for surgeons exploring the para- and retro-pharyngeal space (Figure 7) (Lang, 1995).

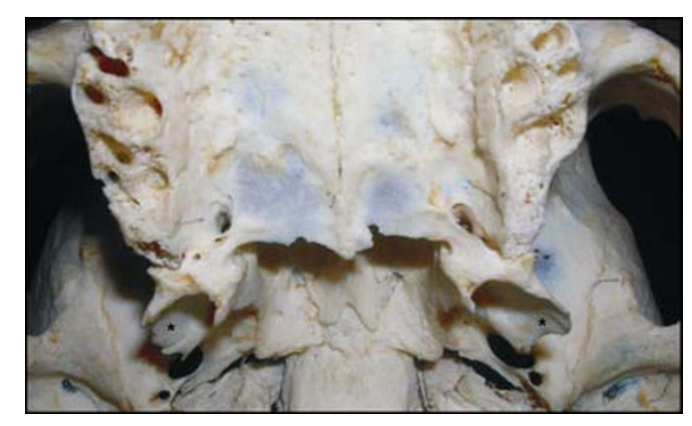

Figure 7 A male skull with enlarged lateral pterygoid plates bilaterally 


\section{The lateral pterygoid muscle}

When the pterygoid muscles contract, both the IAN and the LN may be compressed (Akita et al., 2001). Akita et al. (2000) noted the presence of an aberrant band of muscle arising from the anteromedial aspect of the temporalis and interdigitating with fibers from the LPt. The aberrant muscle could potentially impinge upon either the $\mathrm{LN}$ or the IAN or possibly even act as a point of compression for the MA or its nearby branches. Shimokawa et al. (1998) reported that these variations may result in entrapment or compression of the MN with resultant TGN. They observed the $\mathrm{LN}$ to penetrate the lateral part of the MPt in one of eight cadavers.

Entrapment neuropathies are specific forms of compressive neuropathies that occur when the nerves are interlocked between muscle fibers or confined to narrow anatomic passageways, and are therefore susceptible to constricting pressures. During muscle action, the inflammatory edema due to fasciitis around the nerves decreases blood flow and conduction block. The compression by a hyperactive muscle may result in neuralgia-like paroxysmal pain (Shimokawa et al., 1998). Compression of the sensory branches of the MN by the masticatory muscles is a possible cause of neuropathy (neuralgia or paresthesia) (Shimokawa et al., 1998). LN compression caused numbness, dysaesthesia, paraesthesia, dysgeusia, difficulty with chewing and loss of gustatory function in the side of the compression. Myofibrositis, myositis, or myospasm in the LPt may lead to nerve compression and subsequent loss of sensitivity within its area of distribution (Shimokawa et al., 1998).

Isberg et al., (1987) found LN entrapment in the inferior head of the LP in three of 52 specimens. They suggested that spasm in the muscle could cause LN compression and subsequent loss of sensitivity within its area of distribution. The spasm of the muscle could cause numbness of the tongue some anesthesia or paresthesia mostly affecting the tip of the tongue causing speech articulation problems. When the muscle relaxes, the compression of the nerve ceased and the sensitivity returned to normal, with a re-establishment of normal speech. Loughner et al. (1990) found in three of 52 dissections that the three main branches of the posterior trunk of the MN (LN, IAN and ATN nerves) passed through the medial fibers of the lower belly of the lateral pterygoid muscle. The two nerve entrapments were observed bilaterally and concerned the same specimen. Skrzat et al., (2005) established an atypical course of the LN and its entrapment on the inferior head of the LPt in three out of 52 dissected cadavers. Because of the fact that the anastomosis area of the lingual nerve through the chorda tympani was not compressed, the researchers assumed that the sense of taste for both anterior two thirds of the tongue is not affected from the lingual nerve entrapment.

Chronic and progressive LN compression can destroy the neural axes of the entrapped area and convey a second-degree neural trauma. In this case, nerve decompression does not restore tongue sensibility, thus emphasizing the importance of a prompt diagnosis of nerve entrapment (Sunderland, 1978).

\section{Conclusions}

According to the above-mentioned bibliographical data, cases of tongue numbness, paresthesia, hypoesthesia or anesthesia of the anterior part of the tongue and gums must not be considered as nondiagnosable until the doctor conducts a thorough examination of the area, looking for possible LN entrapment in different locations. When pain of unknown origin exists in the trigeminal region, one has to consider the fact that sensory branches of the MN penetrate muscles innervated by its motor branches. In a strict theoretical basis, any muscle contraction with or without hypertrophy of the LPt might cause a compression of the nerve and its branches.

A wider lateral pterygoid plate may pose difficulty for surgeons and anesthetists exploring the para- and retro-pharyngeal space. In addition, the anatomical knowledge of osseous bridges of the cranial base and their variations could ameliorate our understanding of complex clinical neuralgias in the oral and maxillofacial area and contribute to the effectiveness of surgical interventions. This is why maxillofacial surgeons and dentists must be very suspicious of these phenomena in order to be 
able to interpret neurovascular compression as a result of nerve compression in the infratemporal fossa.

\section{References}

Akita K, Shimokawa T, Sato T (2000). Positional relationships between the masticatory muscles and their innervating nerves with special reference to the lateral pterygoid and the midmedial and discotemporal muscle bundles of temporalis. J Anat, 197(Pt 2): 291-302.

Akita K, Shimokawa T, Sato T (2001). Aberrant muscle between the Temporalis and the Lateral Pterygoid Muscles: M. pterygoideus proprius (Henle). Clin Anat, 14(4): 288-291.

Antonopoulou M, Piagou M, Anagnostopoulou S (2008). An anatomical study of the pterygospinous and pterygoalar bars and foramina - their clinical relevance. $J$ Craniomaxillofac Surg, 36(2): 104-108.

Chouke KS (1946). On the incidence of the foramen of Civinini and the porus crotaphitico-buccinatorius in American Whites and Negroes: I. Observations on 1544 skulls. Am J Phys Anthropol, 4(2): 203-225.

Chouke KS (1947). On the incidence of the foramen of Civinini and the porus crotaphitico-buccinatorius in American Whites and Negroes: II. Observations on 2745 additional skulls. Am J Phys Anthropol, 5(1): 7986.

Chouke KS (1949). Injection of mandibular nerve and gasserian ganglion;an anatomic study. Am J Surg, 78(1): 80-85.

Chouke KS, Hodes PJ (1951). The ptergoalar bar and its recognition by Roentgen methods in trigeminal neuralgia. Am J Roentgenol, 65(2): 180-182.

Civinini F (1837). Ligamento pterigo-spinoso trovato, descritto demonstrato da Filippo Civinini Pistoiese nel. Arch sc med-fis Toscane, 1: 381-387. As cited by: Tebo HG. 1968.

Das S, Paul S (2007). Ossified pterygospinous ligament and its clinical implications. Bratisl Lek Listy, 108(3): 141-143.

De Froe, Wagennar JH (1935). Bedeutung des Porus crotaphitico-buccinatorius und des Foramen pterygospinosum für Neurologie und Röntgenologie. Fortschr Röntgenstr, 52: 64-69.

De Villiers H (1968). The skull of the African Negro. Johannesburg: Witwatersrand University Press, pp155161.

Hyrtl J (1862). Uber den Porus crotaphitico-buccinatorius beim Menschen, Sitzungsb, Kaiserl, Akad, Wissensch, Wien. Natur-Mathem, 46: 111-115. As cited by Tebo HG. 1968.

Isberg AM, Isacsson G, Williams WN, Loughner BA (1987). Lingual numbness and speech articulation deviation associated with temporomandibular joint disk displacement. Oral Surg Oral Med Oral Pathol, 64(1): 9-14.

James TM, Presley R, Steel FL (1980). The foramen ovale and sphenoidal angle in man. Anat Embryol (Berl), 160(1): 93-104.

Kapur E, Dilberović F, Redzepagić S, Berhamović E (2000). Variation in the lateral plate of the pterygoid process and the lateral subzygomatic approach to the mandibular nerve. Med Arh, 54(3): 133-137.

Kim SY, Hu KS, Chung IH, Lee EW, Kim HJ (2004). Topographic anatomy of the lingual nerve and variations in communication pattern of the mandibular nerve branches. Surg Radiol Anat, 26(2): 128-135.

Kopell HP, Thompson WAL (1976). Peripheral entrapment neuropathies.New York: RE Krieger Publishing Company, pp1-7.

Krmpotić-Nemanić J, Vinter I, Jalsovec D (2001). Accessory oval foramen. Ann Anat, 183(3): 293-295.

Krmpotić-Nemanić J, Vinter I, Hat J, Jalsovec D (1999). Mandibular neuralgia due to anatomical variations. Eur Arch Otorhinolaryngol, 256(4): 205-208.

Lang J (1995). Skull base and related structures. Schattauer: Stuttgart, pp300-311.

Lang J, Hetterich A (1983). Postnatal development of the pterygoid process. Anat Anz, 154(1): 1-31.

Lepp FH, Sandner O (1968). Anatomic-radiographic study of ossified pterygospinous and "innominate" ligaments. Oral Surg Oral Med Oral Pathol, 26(2): 244-260.

Loughner BA, Larkin LH, Mahan PE (1990). Nerve entrapment in the lateral pterygoid muscle. Oral Surg Oral Med Oral Pathol, 69(3): 299-306.

Nayak SR, Rai R, Krishnamurthy A, Prabhu LV, Ranade AV, Mansur DI, et al. (2008). An unusual course and entrapment of the lingual nerve in the infratemporal fossa. Bratisl Lek Listy, 109(11): 525-527.

Newton TH, Potts DG (1971). Radiology of the skull and brain, Vol.1. St Louis: I. Mosby, pp307.

Ozdoğmuş O, Saka E, Tulay C, Gürdal E, Uzün I, Cavdar S (2003). The anatomy of the carotico-clinoid foramen and its relation with the internal carotid artery. Surg Radiol Anat, 25(3/4): 241-246.

Patnaik VVG, Singla Rajan K, Bala Sanju (2001). Bilateral pterygo-alar bar and porus crotaphitico buccinatorius- 
A case report. J Anat Soc India, 50(2): 161-162.

Peker T, Karaköse M, Anil A, Turgut HB, Gülekon N (2002). The incidence of basal sphenoid bony bridges in dried crania and cadavers: Their anthropological and clinical relevance. Eur J Morphol, 40(3): 171-180.

Peuker ET, Fischer G, Filler TJ (2001). Entrapment of the lingual nerve due to an ossified pterygospinous ligament. Clin Anat, 14(4): 282-284.

Prades JM, Timishenko A, Merzougui N, Martin C (2003). A cadaveric study of a combined trans-mandibular and trans-zygomatic approach to the infratemporal fossa. Surg Radiol Anat, 25(3/4): 180-187.

Rusu MC, Nimigean V, Podoleanu L, Ivaşcu RV, Niculescu MC (2008). Details of the intralingual topography and morphology of the lingual nerve. Int J Oral Maxillofac Surg, 37(9): 835-839.

Shaw JP (1993). Pterygospinous and pterygoalar foramina: A role in the etiology of Trigeminal Neuralgia? Clin Anat, 6(3): 173-178.

Shimokawa T, Akita K, Soma K, Sato T (1998). Innervation analysis of the small muscle bundles attached to the temporalis: truly new muscles or merely derivatives of the temporalis? Surg Radiol Anat, 20(5): 329-334.

Skrzat J, Walocha J, Srodek R (2005). An anatomical study of the pterygoalar bar and the pterygoalar foramen. Folia Morphol, 64(2): 92-96.

Sunderland S (1978). Nerves and nerve injuries. New York: Churchill Livingstone, pp343-350.
Tebo HG (1968). The pterygospinous bar in panoramic roentgenography. Oral Surg Oral Med Oral Pathol, 26(5): 654-657.

Trost O, K azemi A, Cheynel N, Benkhadra M, Soichot P, Malka G, et al. (2009). Spatial relationships between lingual nerve and mandibular ramus: original study method, clinical and educational applications. Surg Radiol Anat, 31(6): 447-452.

von Lüdinghausen M, Kageyama I, Miura M, Alkhatib M (2006). Morphological pecularities on the deep infratemporal fossa in advanced age. Surg Radiol Anat, 28(3): 284-292.

Wood-Jones F (1931). The Non-metrical morphological characters of the skull as criteria for racial diagnosis: Part I: General discussion of the morphological characters employed in racial diagnosis. J Anat, 65(Pt 2): 179-195.

Wood-Jones F (1931). The non-metrical morphological characters of the skull as criteria for racial diagnosis: Part II: The non-metrical morphological characters of the Hawaiian skull. J Anat, 65(Pt 3): 368-378.

Yoshimasu F, Kurland LT, Elveback LR (1972). Tic douloureux in Rochester, Minnesota, 1945-1969. Neurology, 22(9): 952-956.

Zakrzewska JM (1990). Medical management of trigeminal neuralgia. Br Dent J, 168(10): 399-401.

Zur KB, Mu L, Sanders I (2004). Distribution pattern of the human lingual nerve. Clin Anat, 17(2): 88-92.

\footnotetext{
*Corresponding author: Maria N. Piagkou

Address: Department of Anatomy, Medical School, University of Athens, 9 Kontoyiannaki Street, 11526 N. Psychico, Athens, Greece.

Tel: $302106924507,302106914378 \quad$ Fax: $302107462398 \quad$ E-mail: mapian@med.uoa.gr
} 